\title{
El derecho al matrimonio: \\ un modelo para armar ${ }^{1,2}$
}

Miguel Pachas Serrano ${ }^{3}$

Universidad Científica del Sur

miguelpachasserrano@gmail.com

\section{RESUMEN}

En el presente trabajo se afirma que el derecho al matrimonio, regulado en la Constitución Política de 1993, garantiza su ejercicio a las personas del mismo sexo que deseen hacer vida en común. Para ello, el autor nos recuerda la tradición liberal democrática en la que se inserta la Constitución peruana. Luego expresa los criterios interpretativos a utilizar en el presente artículo. A continuación, desarrolla los principios de autonomía, igualdad y no discriminación y dignidad humana vinculados al ejercicio del derecho al matrimonio. Finalmente, con este marco teórico pasa a analizar el ordenamiento jurídico del matrimonio y tres anteproyectos de ley sobre las uniones de hecho para personas del mismo sexo que deseen hacer vida común. El interés por estas reside en hacer dialogar la implícita noción de matrimonio que contienen con la propuesta del autor.

\section{PALABRAS CLAVE}

Derechos fundamentales, derechos humanos, autonomía personal, derecho a la igualdad y no discriminación, dignidad de la persona humana, derecho al matrimonio, Estado laico.

1 Al igual que Antonio Baylos y Juan José Moreso, tomo el título del presente trabajo de la obra 62 / Modelo para armar, de Julio Cortázar.

2 Quiero agradecer a Samuel Abad por la lectura del presente trabajo y por sus críticas y sugerencias. Por supuesto que la responsabilidad de cualquier cuestionamiento que se exprese es solo mía.

3 Abogado, profesor de la Escuela Académica de Derecho de la Universidad Científica del Sur. 


\section{ABSTRACT}

In this paper states that the right to marriage, regulated under the 1993 Constitution guarantees the exercise of the same sex who wish to live together. For this, the author reminds us of the liberal-democratic tradition in which the Peruvian Constitution is inserted. Then express interpretive used in this Article criteria. Then develops the principles of autonomy, non-discrimination and equality and human dignity related to the exercise of the right to marry. Finally, this framework will now examine the law of marriage and three draft laws on civil unions for same-sex couples wishing to common life. The interest in these talks lies in making the implicit notion of marriage containing the proposal of the author.

\section{KEY WORDS}

Fundamental rights, human rights, personal autonomy, the right to equality and non-discrimination, Human person dignity, right to marriage, secular state.

En el Perú de hoy no existe una única estructura familiar; es posible apreciar estructuras familiares matrifocales, nuclear, extendidas, etc. Por otra parte, hay una mayor visibilidad de los colectivos gay, trans, lésbicos y bisexuales, y que, evidentemente, muchas de estas personas han expresado su voluntad de hacer vida en común, contribuyendo a diversificar la estructura familiar peruana. Pues bien, este nuevo tipo de familia que se presenta en nuestra sociedad no encuentra protección en nuestro ordenamiento jurídico. En esta situación, la desprotección y el abuso han sido la regla general.

Ante esta realidad, desde el Legislativo se han propuesto tres anteproyectos de ley. El primero, presentado el 12 de setiembre de 2013 por el congresista Carlos Bruce, es el Proyecto de Ley 2647/2013-CR, Ley que Establece la Unión Civil no Matrimonial para Personas del mismo Sexo 4 . El segundo, presentado el 21 de octubre pasado por el congresista Julio Rosas, Proyecto de Ley 2801/2013-CR, Ley de Atención Mutua ${ }^{5}$.Y el tercero, presentado el 14 de marzo del presente año por la congresista Martha

4 Consultado el 5 de marzo de 2014 de http://www2.congreso.gob.pe/Sicr/TraDocEstProc/ CLProLey2011.nsf

5 Consultado el 5 de marzo de 2014 de http://www2.congreso.gob.pe/Sicr/TraDocEstProc/ CLProLey2011.nsf 
Chávez, Proyecto de Ley 3273/2013-CR, Ley del Régimen de Sociedad Solidaria6.

Antes de entrar al tema que nos ocupa, llama la atención la correspondencia de los términos empleados en estos anteproyectos con los términos de la institución del matrimonio. Al leer el contenido, se trasluce una equivalencia - casi exacta - con el ordenamiento jurídico del matrimonio; se regulan la definición legal de unión civil, la inscripción de las uniones civiles, la prueba de la libre expresión de voluntad de los solicitantes, los derechos y deberes de los compañeros civiles, los impedimentos para constituir una unión civil, la disolución de la unión civil y su procedimiento, la nulidad de la unión civil y la celebración de contratos que regulen las relaciones personales y efectos patrimoniales de la convivencia y compensaciones económicas en caso de disolución de la unión civil.

Esta circunstancia nos lleva a preguntarnos si el ejercicio del derecho a contraer matrimonio incluye a las personas del mismo sexo o con identidad sexual, identidad de género y orientación sexual distinta de los heterosexuales. Más exactamente, si sería constitucional la ampliación del ejercicio del derecho a contraer matrimonio a las personas del mismo sexo. Pues bien, el propósito de este trabajo es determinar si es posible argumentar que la eventual ampliación del ejercicio del derecho a contraer matrimonio a las personas del mismo sexo sería constitucional.

En cuanto al desarrollo del presente artículo, tenemos, en primer lugar, una breve referencia a la tradición liberaldemocrática en la que se inscribe nuestra Constitución. En segundo lugar, señalaremos los criterios interpretativos que utilizaremos. En tercer lugar, mencionaremos los principios vinculados con el tema que tratamos. En cuarto lugar, presentaremos una propuesta de interpretación del artículo 4 de la Constitución Política del Perú de 1993 sobre el ejercicio y goce del derecho al matrimonio. Y, en quinto lugar, las conclusiones.

\section{La tradición liberal democrática del constitucionalismo peruano}

Es necesario recordar que nuestra Constitución se inscribe - con sus marchas y contramarchas - en la tradición liberal democrática; es decir, que nuestro modelo de convivencia política se basa en la conjunción de los principios del liberalismo como de la democracia: los derechos fundamentales de los individuos y los límites al poder del Estado (libertad, negativa y positiva o autonomía) y sistema de representación democrática

6 Consultado el 5 de marzo de 2014 de http://www2.congreso.gob.pe/Sicr/TraDocEstProc/ CLProLey2011.nsf 
(igualdad), respectivamente ${ }^{7}$; es decir, una conjunción entre libertad (negativa o positiva o autonomía) e igualdad. Junto a ello hay que considerar los valores y técnicas del constitucionalismo: las garantías frente al ejercicio arbitrario del poder estatal o paraestatal, la separación entre el Estado y la Iglesia, la división de poderes, la adopción del principio de mayoría, la Constitución como norma jurídica, la jurisdicción constitucional, etc.

Ahora bien, al recordar esta tradición, en la que se inserta la Constitución peruana, ofrece la ventaja de centrar el debate, desde sus inicios, entre la autonomía y la igualdad; solo así estaremos en condiciones de determinar si la pretensión de las personas del mismo sexo de ejercer su derecho al matrimonio tiene encaje o no en esta tradición política.

\section{Criterios interpretativos}

1. Principio de interpretación de los derechos fundamentales conforme a los tratados de derechos humanos

De acuerdo con el Tribunal Constitucional, los instrumentos internacionales sobre derechos humanos de los que el Estado peruano es parte integran el ordenamiento jurídico ${ }^{\circ}$. En tal sentido, el Tribunal Constitucional ha afirmado que los tratados «son derecho válido, eficaz y, en consecuencia, inmediatamente aplicable al interior del Estado». Esto significa en un plano más concreto que los derechos humanos enunciados en los tratados que conforman nuestro ordenamiento vinculan a los poderes públicos y, dentro de ellos, ciertamente, al legislador ${ }^{10}$.

Por otra parte y de modo complementario a lo dicho por el Tribunal Constitucional, los derechos humanos pueden ser considerados como una teoría de la justicia liberal basada en derechos que se sustentan en los principios de autonomía, inviolabilidad y dignidad de la persona, y el de ciudadanía, cuyo fundamento último se encuentra en la consideración de los individuos como agentes morales ${ }^{11}$.

Pues bien, los derechos humanos como una teoría de la justicia basada en derechos hace referencia a una determinada propuesta ideal de ordenación social que ofrece posibles respuestas — constitucionales-a

7 Barbera 2000: 25-29 y 290. Bovero 2002: 73 y ss.

8 Barbera 2000: 4.

9 Artículo 55 de la Constitución Política del Perú de 1993: «Los tratados celebrados por el Estado y en vigor forman parte del derecho nacional».

10 Exp. 0025-2005-PI/TC y 0026-2005-PI/TC, Colegio de Abogados de Arequipa y otros, demanda de inconstitucionalidad contra parte de la Ley 26397, FJ. 23. Consultado el 5 de marzo de 2014 de http://www.tc.gob.pe/jurisprudencia/2006/00025-2005-Al\%20000262005-Al\%20Admisibilidad.html

11 González Amuchastegui 2004: 494. 
los principales problemas de la convivencia humana en sociedad ${ }^{12}$. Los derechos humanos actúan como parámetro ético para juzgar la legitimidad de las instituciones, de las Constituciones y las leyes, y la actuación de las autoridades. En este contexto, los derechos humanos nos permiten diseñar un modelo ideal del ordenamiento jurídico del matrimonio, a partir del cual podemos cuestionar la regulación del matrimonio en nuestro ordenamiento jurídico ${ }^{13}$.

\section{Principio de unidad de la Constitución}

Por el cual la interpretación de la Constitución se encamina a salvaguardar la unidad de la Constitución como lugar de partida de todo el sistema jurídico ${ }^{14}$. En otras palabras, la interpretación de la Constitución se realiza a partir de su consideración como un todo, desde el cual se establece el sistema jurídico en su totalidad ${ }^{15}$.

\section{Principio de concordancia práctica}

Dispone que «toda aparente tensión entre las propias disposiciones constitucionales debe ser resuelta "optimizando" su interpretación, es decir, sin "sacrificar" ninguno de los valores, derechos o principios concernidos, y teniendo presente que [...] todo precepto constitucional, incluso aquellos pertenecientes a la denominada "Constitución orgánica", se encuentran reconducidos a la protección de los derechos fundamentales, como manifestaciones del principio-derecho de la dignidad humana, cuya defensa y respeto es el fin supremo de la sociedad y el Estado [...]» ${ }^{16}$.

\section{Principio de función integradora}

Establece que la Constitución es un instrumento de cohesión y no de desunión política de la comunidad ${ }^{17}$. Es decir, solo será válida la interpretación que coadyuve a integrar, pacificar y ordenar las conexiones entre los poderes públicos y entre estos y la sociedad en su totalidad ${ }^{18}$.

12 González Amuchastegui 2004: 32.

13 Mutatis mutandis, los derechos fundamentales reconocidos por la Constitución Política del Perú de 1993 pueden considerarse como una teoría de la justicia especial válida para el Perú.

14 Pérez Royo 2007: 128.

15 Exp. 5854-2005-PA/TC, Pedro Andrés Lizana Puelles contra la sentencia de la Segunda Sala Especializada en lo Civil de la Corte Superior de Justicia de Piura, FJ. 12.a. Consultado el 5 de marzo de 2014 de http://www.tc.gob.pe/jurisprudencia/2005/05854-2005-AA.html 16 Exp. 5854-2005-PA/TC, ob. cit., fj.12.b.

17 Pérez Royo 2007.

18 Ob. cit., fj. $12 . d$. 


\section{Principio de fuerza normativa de la Constitución}

«La interpretación constitucional debe encontrarse orientada a relevar y respetar la naturaleza de la Constitución como norma jurídica, vinculante in toto y no solo parcialmente. Esta vinculación alcanza a todo poder público [...] y a la sociedad en su conjunto» ${ }^{19}$.

\section{Principios constitucionales}

A continuación, desarrollaremos los principios constitucionales de autonomía personal, igualdad y no discriminación y dignidad de la persona humana, con la finalidad de lograr una mejor comprensión del derecho al matrimonio.

\section{La autonomía personal}

El que nuestra Constitución se inscriba en la tradición liberal democrática presupone entender al ser humano como individuo racional e independiente ${ }^{20}$. Racional en el sentido de que sus creencias «son contrastables racionalmente ${ }^{21}$. E independiente entendido como que las pautas de valoración autocritica se basan en argumentos y evidencias examinados y consentidos racionalmente y no por la voluntad de terceros ${ }^{22}$.

Pues bien, cuando este individuo actúa de modo racional e independiente, decimos que actúa con autonomía personal. Esto significa que «todos los individuos pueden elaborar libremente sus planes de vida, que pueden ser dueños de su destino, que este no puede quedar en manos de instancias extrañas a los citados individuos ${ }^{23}$.

La autonomía personal no está reconocida como derecho en la Constitución Política del Perú de 1993, pero goza de protección a través del conjunto de derechos fundamentales, los cuales garantizan a los individuos el ejercicio de las facultades y elementos oportunos para realizar decisiones autónomas ${ }^{24}$.

Para garantizar la autonomía personal, corresponde a los poderes públicos -el Estado-, en primer lugar, la creación de pautas o reglas jurídicas que aseguren a los individuos la posibilidad de realizar sus planes de vida; entre estos, el de dos personas con identidad sexual, identidad de género y orientación sexual de ejercer el derecho a contraer matrimonio. Es decir, la autonomía obliga a los poderes públicos «a crear las

19 Ob. cit., fj. 4e.

20 Álvarez 2002: 153 y ss.

21 Laporta 2007: 26.

22 Laporta 2007: 27.

23 González Amuchastegui 2004: 373.

24 Álvarez 2002: 169. 
precondiciones necesarias para la elección y materialización de todas aquellas acciones que no afectan sustancialmente la autonomía de otras personas» ${ }^{25}$. En segundo lugar, sancionar todas aquellas conductas que vulneren las reglas jurídicas arriba mencionadas y que produzcan un daño en los bienes de terceras personas ${ }^{26}$.

Además, los poderes públicos no deben imponer una determinada moral o creencia religiosa a través del derecho; es decir, no debe usarse el derecho para imponer determinados valores morales y religiosos ${ }^{27}$. Esto -en primer lugar - en razón a que la sociedad peruana es una sociedad plural en la que coexisten formas de vida, pautas morales, religiosas y culturales diversas «compatibles con la igual ciudadanía» ${ }^{28}$ regulada en nuestra Constitución.

Y, en segundo lugar, de la concordancia de los artículos 2.2 (igualdad y no discriminación), 2.3 (libertad de conciencia, religión, ideológica, opinión), 2.4 (libertad de expresión) y 2.7 (intimidad personal) ${ }^{29}$ de la Constitución se puede establecer el deber del Estado de abstenerse de favorecer o imponer una determinada moral o creencia religiosa a través de las disposiciones o enunciados normativos; en otras palabras, estos artículos configuran el deber de neutralidad del Estado respecto de las concepciones morales y religiosas de los ciudadanos y ciudadanas ${ }^{30,31}$.

Finalmente, la Corte Interamericana de Derechos Humanos ha señalado que existe una relación entre autonomía individual y orientación sexual; la Corte ha afirmado que «la orientación sexual de una persona también se encuentra ligada al concepto de libertad y la posibilidad de todo ser humano de autodeterminarse y escoger libremente las opciones y circunstancias que le dan sentido a su existencia, conforme a sus propias opciones y convicciones [...] $»^{32}$.

\footnotetext{
25 Fernández Valle 2008: 610.

26 González Amuchastegui 2004: 396.

27 Colomer 2002: 181-182.

28 Colomer 2002: 179.

29 Estos, a su vez, concordados con el artículo 50 de la Constitución Política del Perú de 1993. Desde esta perspectiva, se plantea el problema del sentido y alcance de la última parte del mencionado artículo: «[...] y le presta su colaboración».

30 Malem 2003: 60.

31 Respecto de este último tema, debemos precisar que existen otras maneras de imponer una determinada moral a través del derecho; por ejemplo, excluyendo del ejercicio de ciertos derechos fundamentales a una minoría sexual. Tal sería el caso si se negase el ejercicio del derecho a contraer matrimonio a los gays y lesbianas, etc. Otra forma sería mediante la omisión legislativa, que dificultaría a un grupo de ciudadanos y ciudadanas la concreción de sus planes de vida.

32 Corte Interamericana de Derechos Humanos, Caso Atala Riffo y niñas vs. Chile, sentencia del 24 de febrero de 2012, fj. 136. Consultado el 5 de marzo de 2014 de http://corteidh.or.cr/ docs/casos/articulos/seriec_239_esp.pdf
} 


\section{La igualdad y no discriminación}

La igualdad, en principio, alude al reconocimiento de que todas las personas naturales gozan de la titularidad y ejercicio de los mismos derechos fundamentales ${ }^{33}$. Y la discriminación es una desigualdad antijurídica que se produce por violación del principio de igualdad ${ }^{34}$; «es decir, en el desigual tratamiento de las diferencias que este tutela por igual o en la frustrada satisfacción de los derechos [...] conferidos a todos también por igual $\rangle^{35}$.

Respecto a la igualdad, el Tribunal Constitucional ha señalado «que la igualdad [...] [en] cuanto principio, constituye el enunciado de un contenido material objetivo que, en tanto componente axiológico del fundamento del ordenamiento constitucional, vincula de modo general y se proyecta sobre todo el ordenamiento jurídico. En cuanto derecho fundamental, constituye el reconocimiento de un auténtico derecho subjetivo, esto es, la titularidad de la persona sobre un bien constitucional, la igualdad, oponible a un destinatario. Se trata del reconocimiento de un derecho a no ser discriminado por razones proscritas por la propia Constitución (origen, raza, sexo, idioma, religión, opinión, condición económica) o por otras («motivo» «de cualquier otra índole») que, jurídicamente, resulten relevantes. En cuanto constituye un derecho fundamental, el mandato correlativo derivado de aquel, respecto a los sujetos destinatarios de este derecho (Estado y particulares), será la prohibición de discriminación. Se trata, entonces, de la configuración de una prohibición de intervención en el mandato de igualdad"36.

A su vez, la Corte Interamericana de Derechos Humanos ha señalado que el principio de igualdad y no discriminación «pertenece al jus cogens, puesto que sobre él descansa todo el andamiaje jurídico del orden público nacional e internacional y es un principio fundamental que permea todo ordenamiento jurídico ${ }^{37}$. Hoy día no se admite ningún acto jurídico que entre en conflicto con dicho principio fundamental, ni se admiten tratos discriminatorios en perjuicio de ninguna persona, por motivos de género, raza, color, idioma, religión o convicción, opinión política o de otra índole, origen nacional, étnico o social, nacionalidad, edad,

33 Ferrajoli 2011: 742-743.

34 Ferrajoli 2011: 747.

35 Loc. cit.

36 Exp. 0045- 2004-PI/TC, Demanda de inconstitucionalidad interpuesta por el Colegio de Abogados del Cono Norte de Lima, contra el artículo 3 de la Ley 27466, modificatoria de la Ley Orgánica del Consejo Nacional de la Magistratura, f. 20. Consultado el 5 de marzo de 2014 de http://www.tc.gob.pe/jurisprudencia/2006/00045-2004-Al.html

37 El resaltado es nuestro. 
situación económica, patrimonio, estado civil, nacimiento o cualquier otra condición $»^{38}$.

Este principio impone al Estado peruano, en primer lugar, la obligación de inhibirse de realizar actos que de cualquier modo se dirijan, directa o indirectamente, a implantar condiciones de discriminación de jure o de facto $^{39}$. Y, en segundo lugar, la obligación de favorecer medidas positivas para revertir o cambiar realidades discriminatorias existentes en el Perú, en detrimento de algún grupo de personas. «Esto implica el deber especial de protección que el Estado debe ejercer con respecto a actuaciones y prácticas de terceros que, bajo su tolerancia o aquiescencia, creen, mantengan o favorezcan las situaciones discriminatorias» ${ }^{40}$.

Respecto a la no discriminación, la Observación General 20 que desarrolla el artículo 2 del Pacto Internacional de Derechos Económicos, Sociales y Culturales establece que «toda distinción, exclusión, restricción o preferencia u otro trato diferente que directa o indirectamente se base en los motivos prohibidos de discriminación y que tenga por objeto o por resultado anular o menoscabar el reconocimiento, goce o ejercicio ${ }^{41}$, en condiciones de igualdad, de los derechos reconocidos en el Pacto. La discriminación también comprende la incitación a la discriminación y el acoso» ${ }^{42}$.

Entre los motivos prohibidos de discriminación, la observación citada, incluye dentro de la expresión otra condición social, la orientación sexual y la identidad de género, por la cual el Estado peruano debe «cerciorarse de que las preferencias sexuales de una persona no constituyan un obstáculo para hacer realidad los derechos que reconoce el Pacto, por ejemplo, a los efectos de acceder a la pensión de viudedad. La identidad de género también se reconoce como motivo prohibido de discriminación. Por ejemplo, los transgénero, los transexuales o los intersexo son víctimas frecuentes de graves violaciones de los derechos humanos, como el acoso en las escuelas o en el lugar de trabajo» ${ }^{43}$.

38 Corte Interamericana de Derechos Humanos, Opinión Consultiva OC-18/03 de 17 de setiembre de 2003, solicitada por los Estados Unidos Mexicanos, Condición Jurídica y Derechos de los migrantes indocumentados, párr. 101. Consultado el 5 de marzo de 2014 de http:// www.corteidh.or.cr/docs/opiniones/seriea_18_esp.pdf

39 Corte Interamericana de Derechos Humanos (2003), párr. 103.

40 Corte Interamericana de Derechos Humanos (2003), párr. 104.

41 Las cursivas y negritas son nuestras.

42 Naciones Unidas, Observación General 20. La no discriminación y los derechos económicos, sociales y culturales (artículo 2, párrafo 2 Pacto Internacional de Derechos Económicos, Sociales y Culturales), párr. 7. Consultado el 5 de marzo de 2014 de http://tbinternet.ohchr. org/_layouts/treatybodyexternal/Download.aspx?symbolno=E\%2fC.12\%2fGC\%2f20\&Lang =en

43 Observación General 20, loc. cit. 
Igualmente, la Corte Interamericana de Derechos Humanos ha señalado que «el derecho y los Estados deben ayudar al avance social; de lo contrario, se corre el grave riesgo de legitimar y consolidar distintas formas de discriminación violatorias de los derechos humanos» "; por lo que un «derecho que le está reconocido a las personas no puede ser negado o restringido a nadie y bajo ninguna circunstancia con base en su orientación sexual. Ello violaría el artículo 1.1 de la Convención Americana. El instrumento interamericano proscribe la discriminación, en general, incluyendo en ello categorías como las de la orientación sexual, que no puede servir de sustento para negar o restringir ninguno de los derechos establecidos en la Convención» ${ }^{45}$.

\section{La dignidad de la persona humana}

Nos parece que existe acuerdo ${ }^{46}$ en que la idea de dignidad humana sugiere que hay en la existencia de todo ser humano «algo que podemos y debemos considerar inviolable, y que limita el ámbito del discurso moral admisible» ${ }^{47}$. También, en que la dignidad es un valor absoluto en el sentido de que esta y los bienes en que se concretan no tienen precio ni les corresponde comercio alguno ${ }^{48}$.

$Y$ es en esta perspectiva que el Tribunal Constitucional ha señalado que:

De este reconocimiento de la dignidad humana en el derecho constitucional e internacional, se deriva la naturaleza de sus alcances jurídicos, en tanto sustrato axiológico y soporte estructural de la protección debida al individuo, configurándose como «[...] un mínimum inalienable que todo ordenamiento debe respetar, defender y promover» [STC 0010-2002-Al, Caso Marcelino Tineo Silva].

De allí que la dignidad sea caracterizada por la posición preferente que ocupa en el ordenamiento jurídico, y por la individualización respecto del rol de fundamento, fin y límite que a la misma le

44 Corte Interamericana de Derechos Humanos, Caso Atala Riffo y niñas vs. Chile, Sentencia del 24 de febrero de 2012, f. 120. Consultado el 5 de marzo de 2014 de http://corteidh.or.cr/ docs/casos/articulos/seriec_239_esp.pdf

45 Consultado el 5 de marzo de 2014 de http://corteidh.or.cr/docs/casos/articulos/seriec_239_esp.pdf

46 Pareciera que los desacuerdos se presentan cuando queremos determinar ese algo que consideramos inviolable. Para algunos, la noción de dignidad es una noción acabada y cerrada, válida para todo tiempo. Para otros, la dignidad, al contrario de la primera acepción, es un término vago al que se le va dotando de sentido poco a poco, a través del intercambio racional de argumentos en el caso concreto; posición que se condice con una sociedad liberal-democrática.

47 González Amuchastegui 2004: 417.

48 González Amuchastegui 2004: 433. 
corresponde cumplir frente a la existencia de todos los derechos fundamentales ${ }^{49}$.

Me interesa señalar, en primer lugar, que la mejor manera de considerar la dignidad es reconociendo a todas las personas, la titularidad de derechos fundamentales, así como el efectivo ejercicio de estos ${ }^{50}$. Es decir, existe una correlación entre los derechos fundamentales y la dignidad de la persona humana ${ }^{51}$.

Y, en segundo lugar, que el principio de dignidad de la persona humana opera como un límite al poder estatal; es decir, el Estado no podrá, de modo arbitrario, legislar que determinadas personas no podrán ejercer ciertos derechos. Hacerlo significaría vulnerar el Estado constitucional de derecho, la seguridad jurídica y la interdicción de la arbitrariedad ${ }^{52}$.

\section{El derecho al matrimonio}

Nos parece que el problema se centra en la regulación de las condiciones de su ejercicio ${ }^{53}$; más exactamente, si puede ser ejercida por las personas con identidad sexual, identidad de género y orientación sexual distinta de las personas heterosexuales. Para tener claridad sobre este tema, debemos determinar previamente quién o quiénes son titulares del derecho al matrimonio.

\section{El ordenamiento jurídico del matrimonio}

El régimen jurídico del matrimonio está conformado por las disposiciones normativas constitucionales, las del derecho internacional de los derechos humanos y las del derecho civil y la jurisprudencia del Tribunal Constitucional.

En cuanto al Pacto Internacional de Derechos Civiles y Políticos, tenemos que regula en la disposición normativa 23 lo concerniente a la familia y el matrimonio:

1. La familia es el elemento natural y fundamental de la sociedad y tiene derecho a la protección de la sociedad y del Estado.

\footnotetext{
49 Exp. 2273-2005-PHC/TC, Karen Mañuca Quiroz Cabañillas vs. Sala Penal Superior de Emergencia para procesos con reos libres de la Corte Superior de Justicia de Lima, fj. 7. Consultado el 5 de marzo de 2014 de http://www.tc.gob.pe/jurisprudencia/2006/02273-2005HC.html

50 González Amuchastegui 2004: 418.

51 Exp. 2273-2005-PHC/TC, fj. 7.

52 González Amuchastegui 2004: 438.

53 STCE 198/2012, 6 de noviembre de 2012, Cámara de Diputados vs. Estado Español, fj. 11. Consultado el 5 de marzo de 2014 de http://www.tribunalconstitucional.es/ES/JURISPRUDENCIA/Paginas/Sentencia.aspx?cod=20674
} 
2. Se reconoce el derecho del hombre y de la mujer a contraer matrimonio y a fundar una familia si tienen edad para ello.

3. El matrimonio no podrá celebrarse sin el libre y pleno consentimiento de los contrayentes.

4. Los Estados partes en el presente Pacto tomarán las medidas apropiadas para asegurar la igualdad de derechos y de responsabilidades de ambos esposos en cuanto al matrimonio, durante el matrimonio y en caso de disolución del mismo. En caso de disolución, se adoptarán disposiciones que aseguren la protección necesaria a los hijos ${ }^{54}$.

En segundo lugar, la Convención Americana sobre Derechos Humanos regula en la disposición normativa 17 lo concerniente a la familia y el matrimonio:

1. La familia es el elemento natural y fundamental de la sociedad y debe ser protegida por la sociedad y el Estado.

2. Se reconoce el derecho del hombre y la mujer un contraer matrimonio y a fundar una familia si tienen la edad y las condiciones requeridas para ello por las leyes internas, en la medida en que estas no afecten al principio de no discriminación establecido en esta Convención.

3. El matrimonio no puede celebrarse sin el pleno y el libre consentimiento de los contrayentes.

4. Los Estados partes deben tomar medidas apropiadas para asegurar la igualdad de derechos y la adecuada equivalencia de responsabilidades de los cónyuges en cuanto al matrimonio, durante el matrimonio y en caso de disolución del mismo. En caso de disolución, se adoptarán disposiciones que aseguren la protección necesaria de los hijos, sobre la base única del interés y conveniencia de ellos.

5. La ley debe reconocer iguales derechos tanto a los hijos nacidos fuera de matrimonio como a los nacidos dentro del mismo ${ }^{55}$.

Y la disposición normativa del artículo 17.2 señala que:

Se reconoce el derecho del hombre y de la mujer a contraer matrimonio y a fundar una familia si tienen edad y las condiciones requeridas para ello por las leyes internas, en la medida en que estas no afecten al principio de no discriminación establecido en esta Convención ${ }^{56}$.

54 Naciones Unidas, Pacto Internacional de Derechos Civiles y Políticos. Consultado el 5 de marzo de 2014 de http://www.ohchr.org/EN/Professionallnterest/Pages/CCPR.aspx 55 Organización de Estados Americanos, Convención Americana sobre Derechos Humanos. Consultado el 5 de marzo de 2014 de http://www.cidh.oas.org/basicos/basicos2.htm 56 LoC. cit. 


\section{Interpretación de las disposiciones normativas mencionadas}

Conviene recordar que estas disposiciones normativas «son derecho válido, eficaz y, en consecuencia, inmediatamente aplicable al interior del Estado». Esto significa que los derechos humanos enunciados en los tratados que conforman nuestro ordenamiento vinculan a los poderes públi$\cos y$, dentro de ellos, ciertamente, al legislador ${ }^{57}$.

En cuanto a la Constitución Política del Perú de 1993, la disposición normativa constitucional 4 establece el deber del Estado de promover el matrimonio y de regular la forma del matrimonio y de las causales de separación y de disolución.

Ahora bien, para determinar la interpretación más adecuada y que mejor garantice los derechos fundamentales de los ciudadanos y ciudadanas debemos tener presente, en primer lugar, la cuarta disposición final de la Constitución, en virtud de la cual la disposición constitucional antes citada debe interpretarse de conformidad con la Declaración Universal de Derechos Humanos, los instrumentos internacionales de derechos humanos, así como de las decisiones adoptadas por los tribunales internacionales sobre derechos humanos ${ }^{58}$. Y en segundo lugar, los principios de autonomía, igualdad y no discriminación y dignidad de la persona humana.

De la integración de todas las disposiciones normativas antes mencionadas podemos extraer dos disposiciones normativas constitucionales (DNC):

DNC1: «El matrimonio es la unión estable y voluntaria entre un varón y una mujer».

DNC2: «El matrimonio es la unión estable y voluntaria entre dos personas».

De estas, no cabe duda de que la disposición normativa constitucional DNC2 es la que mejor armoniza con los principios de autonomía personal, principio de igualdad y no discriminación y dignidad de la persona humana. Además, permite acercarnos —un poco más- al modelo de convivencia social previsto en la Constitución.

A su vez, el contenido normativo (CN) conjuntivo de la disposición normativa constitucional DNC2 está conformado por las siguientes normas constitucionales, las cuales garantizan la titularidad y el ejercicio del derecho al matrimonio a todos los ciudadanos y ciudadanas:

57 Exp. 0025-2005-PI/TC y 0026-2005-PI/TC, Colegio de Abogados de Arequipa y otros, demanda de inconstitucionalidad contra parte de la Ley 26397, f. 23. Consultado el 5 de marzo de 2014 de http://www.tc.gob.pe/jurisprudencia/2006/00025-2005-Al\%20000262005-AI\%20Admisibilidad.html

58 Artículo V del Título Preliminar del Código Procesal Constitucional, Ley 28237. 
DNC2CN1: «El matrimonio es la unión estable y voluntaria entre dos personas de sexo diferente».

DNC2CN2: «El matrimonio es la unión estable y voluntaria entre dos personas del mismo sexo».

DNC2CN3: «El matrimonio es la unión estable y voluntaria entre dos personas intersexuales, travestis, transgénero, transexuales».

\section{Delimitación del derecho al matrimonio}

De la disposición normativa constitucional DNC2 podemos delimitar el derecho al matrimonio. Los titulares de este derecho son todos los varones y mujeres de acuerdo con el contenido normativo conjuntivo de DNC2 y las que eventualmente sean exigidas por la ley. Asimismo, su objeto es un agere licere, es decir, una libertad. El único que decide (autonomía) darse la norma de casarse es su titular y nadie «puede disponer jurídicamente de su conducta en ese espacio vital o jurídico objeto del derecho fundamental $»^{59}$ al matrimonio. La faceta negativa de esta libertad reside en no contraer matrimonio si uno no anhela hacerlo ${ }^{60}$.

El contenido de este derecho es la unión estable de dos personas - varón y mujer, varón y varón, mujer y mujer e intersexuales, travestis, transgénero, transexuales entre sí-, con la finalidad de fundar una familia, que no incluye la exigencia de la procreación. Los límites generalmente aceptados son: no pueden contraer matrimonio los infantes, la prohibición de la poligamia y del incesto ${ }^{61}$.

\section{La disposición normativa constitucional DNC2 y el Código Civil}

A partir de la disposición normativa constitucional DNC2 podemos aproximarnos a la disposición normativa civil que establece la noción de matrimonio. La cual señala que:

El matrimonio es la unión voluntariamente concertada por un varón y una mujer legalmente aptos para ella y formalizada con sujeción a las disposiciones de este Código, a fin de hacer vida común ${ }^{62}$.

Como podemos observar, hay una aparente contradicción entre la disposición normativa constitucional DNC2 y la disposición normativa civil del matrimonio. Creemos que la vía para salvar esta aparente contradicción podría ser iniciar un proceso de amparo; una especie de amparo

59 Bastida Freijedo y otros 2004: 105

60 Diez Picazo 2003: 413.

61 La primera parte de la disposición normativa constitucional 4, «La comunidad y el Estado promueven el matrimonio», debe entenderse conforme a lo establecido en DN2: «El matrimonio es la unión estable entre dos personas».

62 Artículo 234 del Código Civil peruano. 
interpretativo con la finalidad de que el Tribunal Constitucional realice una interpretación que posibilite el ejercicio del derecho al matrimonio a las personas del mismo sexo, intersexuales, travestis, transgénero, transexuales.

La otra vía sería modificar las disposiciones normativas de los artículos 234 y 326 del Código Civil peruano, para incluir a las personas del mismo sexo, intersexuales, travestis, transgénero, transexuales, así como modificar el artículo 5 de la Constitución.

\section{Continuación: a propósito de la unión civil no matrimonial, la} atención mutua y la sociedad solidaria

A partir de lo expresado líneas arriba, pasaremos a analizar los anteproyectos 2647/2013-CR, Ley que Establece la Unión Civil no Matrimonial para Personas del mismo Sexo ${ }^{63}$; 2801/2013-CR, Ley de Atención Mutua; y 3273/2013-CR, Ley del Régimen de Sociedad Solidaria.

La razón de este acápite se debe a que estos anteproyectos responden a una idea sobre el derecho al matrimonio, que como vemos no se corresponde con lo que hemos señalado hasta el momento. Por ello, presentaremos cuáles son, a nuestro criterio, los principales problemas que presentan estos anteproyectos.

\section{a. Inconsistencia lógica de los anteproyectos}

En los tres anteproyectos se puede observar una identidad material, sobre todo de la unión civil no matrimonial, entre las propuestas y la institución del matrimonio civil. Si en el fondo son idénticas, ¿por qué crear dos instituciones paralelas? ¿Por qué los ciudadanos y ciudadanas con identidad sexual, identidad de género y orientación sexual distinta de los heterosexuales deben tener un régimen matrimonial diferenciado (unión civil no matrimonial)? ¿Es posible justificar la diferencia de régimen en estos casos?

Se puede observar cierta inconsistencia dentro de la exposición de motivos de los tres anteproyectos. En las exposiciones de motivos no encontramos la justificación de este trato diferente: unión civil no matrimonial, atención mutua o sociedad solidaria. Para el caso del anteproyecto Bruce, toda la justificación que desarrolla se orienta a la universalización del ejercicio del derecho al matrimonio, pero no arriba a esta conclusión.

Esta inconsistencia lógica en la argumentación se expresa del siguiente modo: por un lado, se dice que todas las personas tienen derecho al

63 Consultado el 5 de marzo de 2014 de http://www2.congreso.gob.pe/Sicr/TraDocEstProc/ CLProLey2011.nsf 
matrimonio; por otro, que todos los gays, transgénero, lesbianas y bisexuales son personas; entonces todos los gays, transgénero, lesbianas y bisexuales tienen derecho a la unión civil no matrimonial.

La conclusión a la que se arriba en la exposición de motivos, la de tener derecho a la unión civil no matrimonial —en vez de concluir que tienen derecho al matrimonio-, se explica, según nos parece, por dos razones. La primera tiene carácter político, en el sentido de considerar que es mejor ir de menos a más, lo cual es como decir: sí, efectivamente tienen derecho, pero por ahora no conviene que lo ejerzan. La segunda razón se explica por una no adecuada identificación del contenido de la igualdad comprometida en este caso. En el presente apartado no referiremos a esta segunda, ya que la primera escapa a un análisis jurídico constitucional.

Los otros dos anteproyectos también presentan inconsistencias. El anteproyecto de atención mutua, en su exposición de motivos, señala por arte de birlibirloque — sexto párrafo-que «la familia heterosexual y monogámica es la célula básica de la sociedad y cumple funciones insustituibles para el desarrollo integral de cada uno de sus miembros y la convivencia en comunidad ${ }^{64}$. Es decir, se arriba a esta afirmación sin desarrollar una justificación suficiente. En cuanto anteproyecto de sociedad solidaria, la exposición de motivos es mínima e insuficiente.

\section{b. La autonomía personal}

Llegados a este punto, podemos afirmar que los tres anteproyectos implican un esfuerzo de los poderes públicos, en particular del Congreso de la República, de intentar garantizar la autonomía personal -y sus planes de vida - de un sector de ciudadanos y ciudadanas del país. Esfuerzo que desde el punto de vista de la autonomía se encamina a crear las pautas jurídicas para que los ciudadanos y ciudadanas que - por su identidad sexual, identidad de género y orientación sexual- no gocen en la actualidad de los beneficios del matrimonio o de la unión de hecho.

Sin embargo, hay que indicar que de aprobarse alguno de estos anteproyectos no se garantizaría adecuadamente la autonomía personal de las personas del mismo sexo que deseen hacer vida en común, debido a que serían una respuesta insuficiente que no salvaguardaría la igualdad de trato jurídico a todos los ciudadanos y ciudadanas en este asunto. 


\section{c. La igualdad y no discriminación}

Otro problema que presentan los anteproyectos tiene que ver con el principio de igualdad. Para ello, nos preguntamos: ¿que manifestación del principio de igualdad y no discriminación pretenden desarrollar los anteproyectos? Antes, se debe señalar que las situaciones de desigualdad y discriminación no se presentan de modo aislado, por lo que, para determinar qué manifestación del mencionado principio debe prevalecer, se debe tomar en cuenta «el peso simbólico» ${ }^{65}$ de cada una según el caso concreto.

Pues bien, nos parece que la respuesta más adecuada sería la igualdad como exigencia de generalidad o igualdad de trato jurídico ${ }^{66}$, en virtud de la cual todas las personas nos encontramos vinculados a las mismas normas y tribunales. Por ello, la vulneración de la igualdad de trato se manifiesta en la imposibilidad de que las personas trans, lesbianas, gay y bisexuales puedan ejercer el derecho al matrimonio o la unión de hecho reconocidos en la Constitución Política de Perú de 1993, por lo que en principio, desde la perspectiva jurídica, bastaría con hacer verdaderamente universal el ejercicio del derecho al matrimonio y no crear un régimen paralelo al mismo ${ }^{67}$.

También podría argumentarse que los anteproyectos buscan establecer políticas de acción positiva o afirmativa a favor del colectivo de trans, lesbianas, gay y bisexuales. Pero nos parece que la manifestación de la igualdad que se pretende desarrollar con estas medidas es la igualdad de oportunidades y la igualdad de resultados ${ }^{68}$; estas medidas buscan un trato igual respecto al acceso de determinados bienes primarios ${ }^{69} \mathrm{o}$ la eliminación de las trabas, en los diferentes ámbitos de la vida social, que imposibilitan la mejora de las condiciones de la persona humana ${ }^{70}$. Dicho de otro modo, aquí no solo se busca salvaguardar la igualdad de trato, sino también remover las desigualdades de hecho - actitudes, comportamientos y estructuras sociales - que obstan el que seamos titulares y gocemos de los derechos fundamentales. En este sentido, nos parece que los anteproyectos buscan - hacer más universal el ejercicio del derecho al matrimonio - garantizar la seguridad jurídica ${ }^{71}$ de los beneficios materiales que podría producir la eventual unión —unión civil no matrimonial,

65Abramovic y Courtis 2004: 27.

66 Pérez Luño 2007: 22.

67 Evidentemente, en paralelo, el Estado deberá poner en marcha otras medidas para eliminar las prácticas discriminatorias de cualquier tipo.

68 Añón 2001: 59.

69 Alarcón Cabrera 2004: 188.

70 Ferrajoli 2011: 747.

71 Pérez Luño 2007: 24. 
atención mutua o sociedad solidaria entre personas con identidad sexual, identidad de género y orientación sexual distinta de las personas heterosexuales - ; no es una propuesta vinculada a la igualdad de oportunidades.

\section{d. La dignidad de la persona humana}

Volviendo al Tribunal Constitucional, este ha manifestado que el principio de dignidad de la persona humana se caracteriza por su multifuncionalidad que comprende:

enunciativamente de la autonomía, libertad e igualdad humana, siendo que todas ellas en sí mismas son necesidades humanas que emergen de la experiencia concreta de la vida práctica ${ }^{72}$.

Como podemos apreciar, la dignidad de la persona humana está íntimamente vinculada con los principios de autonomía y de igualdad, que son principios rectores de la convivencia política. Por ello, debido a que los anteproyectos no superaron la prueba de la igualdad y no discriminación, y también a causa de la íntima conexión de este principio con la autonomía - ambos componentes importantes del principio de dignidad de la persona-, consideramos que tampoco permitirían una adecuada protección de este último principio.

\section{e. Deber especial de protección del Estado}

De todas las exposiciones de motivos, se desprende que el Estado tiene un deber especial de protección hacia las personas que por su preferencia sexual o identidad sexual, identidad de género y orientación sexual son discriminadas, y se las excluye de los beneficios materiales de ciertos derechos fundamentales - entre ellos, el matrimonio-; se concluye que sí es posible que el Estado establezca un régimen jurídico paralelo para las personas con preferencia sexual o identidad sexual, identidad de género y orientación sexual distinta de las personas heterosexuales. Es decir, la protección que se plantea contraviene las obligaciones internacionales asumidas por el Estado peruano, sobre todo el deber de garantizar la igualdad y no discriminación a todos los ciudadanos.

\section{f. Uso de una categoría sospechosa de discriminación para estable- cer un diferenciación}

Tenemos que la justificación de una diferencia de trato -creación de la unión civil no matrimonial, la atención mutua y la sociedad solidaria-, 
y por lo tanto seguir manteniendo la restricción del ejercicio del derecho al matrimonio, se hace sobre la base del uso de un motivo expresamente prohibido (preferencia sexual o identidad sexual, identidad de género y orientación sexual) por la Constitución y los instrumentos internacionales de derechos humanos, y no presentan argumentos suficientes -objetivos, razonables y proporcionales ${ }^{73}$ - que justifiquen tal medida ${ }^{74}$.

Como consecuencia de lo dicho, nos parece que el legislador no ha realizado un examen adecuado de los anteproyectos con la finalidad de salvaguardar el derecho a la igualdad y no discriminación; en particular, del derecho a la igualdad y no discriminación de las personas con preferencias hacia otra del mismo sexo o identidad sexual, identidad de género y orientación sexual ${ }^{75}$. Esta falta de argumentos rigurosos podría tener el efecto negativo de producir un mayor arraigo de los estereotipos sociales respecto de las personas con preferencia sexual hacia otra del mismo sexo o identidad sexual, identidad de género y orientación sexual diferente de las heterosexuales. Además, debemos vincular este efecto negativo con la exigencia, derivada del principio de igualdad y no discriminación, según la cual toda diferencia de trato no debe servir para mantener o profundizar la estigmatización de los grupos o minorías vulnerables ${ }^{76}$. Y es justamente esta situación la que no es tenida en cuenta por el legislador peruano. No es suficiente que el legislador presente un anteproyecto de ley que permita superar esta situación de discriminación y exclusión social.

Así tenemos que existe en nuestra sociedad una situación de discriminación, ya que el Estado peruano excluye del ejercicio del derecho al matrimonio a ciudadanos y ciudadanas que siendo del mismo sexo desean contraer matrimonio. Situación que se agrava, por ejemplo, cuando el Congreso de la República condecoró a un conocido activista internacional contrario a los derechos de las personas con preferencia hacia otras de su mismo sexo o con identidad sexual, identidad de género y orientación sexual distinta de las heterosexuales. Peor aún cuando el Estado peruano carece de estadísticas oficiales - salvo las proporcionadas por la sociedad civil $^{77}$ - respecto de la situación de estas personas: no se sabe oficialmente cuántas sufren discriminación, cuantas han sufrido violencia psicológica o física o han sido víctimas de crímenes de odio, lo que dificulta

\footnotetext{
73 Ob. cit., f. 124. Consultado el 5 de marzo de 2014 de http://corteidh.or.cr/docs/casos/ articulos/seriec_239_esp.pdf

74 Ob. cit., f. 127 . Consultado el 5 de marzo de 2014 de http://corteidh.or.cr/docs/casos/ articulos/seriec_239_esp.pdf 75 Fernández Valle 2008: 607. 76 Red Peruana TLGB y Promsex: 2013. 77 Fernández Valle 2008: 605 y 613.
} 
diseñar las diferentes políticas, legislativas y públicas, para garantizar la plena vigencia de sus derechos fundamentales.

Por ello, a nuestro parecer, estas propuestas de trato diferente significarían agravar, aún más, la situación social y jurídica de estas personas. Al diferenciarlas se reforzaría en el imaginario social su condición de ciudadanos y ciudadanas de categoría inferior a la de los matrimonios heterosexuales ${ }^{78}$. En nuestro contexto, podría significar reforzar cierto perfeccionismo estatal, social e individual respecto a que la vida matrimonial es, inevitablemente, heterosexual ${ }^{79}$.

Resumiendo, y teniendo en cuenta nuestra realidad sociojurídica, con estos anteproyectos - de convertirse alguno en ley-no se estaría garantizando la igualdad y no discriminación de las personas con identidad sexual, identidad de género y orientación sexual que deseen hacer vida en común. El Estado no estaría promoviendo - como en apariencia pudiera parecer- una mejor convivencia social; lo que estaría haciendo es legitimar no solo aptitudes discriminatorias, sino validar y hacer suyas ciertas concepciones morales y religiosas; incumpliendo de este modo su deber de neutralidad respecto de estas. Ninguno de los proyectos supera el test de igualdad y no discriminación.

\section{Prórroga: continuamos con el Estado. La jerarquía de la Iglesia católica}

Para finalizar, quisiera referirme, en primer lugar, a las opiniones de la Defensoría del Pueblo ${ }^{80}$ y del Ministerio de Justicia ${ }^{81}$ en defensa del anteproyecto Bruce. Y, en segundo lugar, a la opinión de la jerarquía de la Iglesia católica. Dichas opiniones contienen, de modo implícito, una posición respecto del matrimonio entre personas del mismo sexo, que nos servirá para contrastar lo expresado por nosotros.

Además, y respecto de la jerarquía de la Iglesia católica, nos interesan sus opiniones, debido a que esta institución ha ejercido una influencia capaz de ralentizar el modelo de convivencia política que propone la Constitución Política del Perú de 1993.

78 Nino 2013: 308.

79 Defensoría del Pueblo. Consultado el 5 de marzo de 2014 de http://www.defensoria. gob.pe/modules/Downloads/informes/varios/2014/Informe-de-Adjuntia-003-2014-DP-ADHPD-2.pdf

80 Ministerio de Justicia. Consultado el 5 de marzo de 2014 de http://3.elcomercio.e3.pe/ doc/0/0/8/5/1/851029.pdf

81 Fernández Valle 2008: 610. 


\section{a. Opiniones de la Defensoría del Pueblo y del Ministerio de Justicia}

Tanto de las opiniones de la Defensoría del Pueblo como del Ministerio de Justicia podemos hacer extensiva la crítica del subacápite $a$ del acápite 5; ambos contienen una inconsistencia lógica que se expresa del siguiente modo: por un lado, se dice que todas las personas tienen derecho al matrimonio; por otro, que todos los gays, transgénero, lesbianas y bisexuales son personas; entonces, todos los gays, transgénero, lesbianas y bisexuales tienen derecho a la unión civil no matrimonial.

El Ministerio de Justicia señala que el derecho al libre desarrollo de la personalidad es la concreción del valor de la autonomía. Pues bien, si en ejercicio de este valor dos personas del mismo sexo deciden hacer vida en común amparándose en el marco legal de la unión civil no matrimonial, no tendrían inconvenientes, ya que sus planes de vida diseñados a partir del ejercicio pleno de su autonomía encontrarían las pautas normativas para alcanzar tal propósito. ¿Pero qué pasaría si dos personas del mismo sexo deciden hacer vida en común y expresan su voluntad de contraer matrimonio?

Antes es necesario indicar que no debemos olvidar que en nuestra sociedad muchos individuos — sin importar su preferencia sexual- atribuyen al matrimonio una importancia y una centralidad ${ }^{82}$ únicas. En esta línea, el Ministerio de Justicia afirma «que el derecho al libre desarrollo de la persona comprende el poder de decidir libremente con quién contraer matrimonio» ${ }^{83}$. Y es aquí en donde se encuentra el quid del asunto: no concluye que para garantizar, de modo adecuado, el derecho al matrimonio el Estado debe asegurar el ejercicio universal del mismo para todas las personas, heterosexuales u homosexuales.

El ministerio apuesta por la creación de un régimen paralelo a la unión de hecho ${ }^{84}$. Esto se constituye, a nuestro parecer, en una doble estigmatización y discriminación. La primera, al no señalar que el ejercicio del derecho al matrimonio es un derecho fundamental, que el Estado debe garantizarlo a todos los ciudadanos en igualdad de condiciones. La segunda, porque crea un régimen paralelo o diferenciado a partir de una categoría sospechosa de discriminación sin expresar

82 Ministerio de Justicia. Consultado el 5 de marzo de 2014 de http://3.elcomercio.e3.pe/ doc/0/0/8/5/1/851029.pdf

83 Artículo 5 de la Constitución Política del Perú de 1993.

84 Antes de iniciar este acápite, debo expresar mi convicción de la enorme importancia de la religión en la autorrealización de la vida íntima de muchísimos ciudadanos y ciudadanas peruanos y peruanas. Igualmente, debo afirmar que los problemas de convivencia social se resuelven con la política; no con cualquier ideología política, sino con la ideología política del liberalismo democrático, con sus textos jurídicos fundamentales, sus principios y con los aportes del constitucionalismo. 
«argumentos, objetivos, razonables y proporcionales que así lo justifiquen». El Estado dejar pasar una oportunidad para «armar» adecuadamente el ordenamiento jurídico del matrimonio y la unión de hecho para todos los ciudadanos y ciudadanas.

\section{b. Opiniones de la jerarquía de la Iglesia católica ${ }^{85}$}

Comenzaremos precisando que en un Estado laico - como el nuestro- las confesiones religiosas tienen el deber - entre otros- de adaptarse y moderarse para permitir la vida común en democracia. Esto debido a que en una sociedad laica «tienen acogida las creencias religiosas en cuanto derecho de quienes la asumen, pero no como deber que pueda imponerse a nadie» ${ }^{86}$.

Respecto del tema que nos ocupa, la jerarquía de la Iglesia católica plantea un referéndum para que la ciudadanía decida sobre la unión civil no matrimonial. Esta institución se presenta como democrática y, paradójicamente, inicia su performance democrática con una contradicción: nos propone que primero rompamos una de las reglas del juego democrático y de la convivencia social reguladas en la Constitución Política del Perú de 1993: «no pueden someterse a referéndum la supresión o la disminución de los derechos de las personas.... $\rangle^{87}$. De esta forma, incumple su deber de «respetar, cumplir y defender la Constitución y el ordenamiento jurídico de la Nación ${ }^{88}$.

Por otra parte, podemos decir que el último párrafo del artículo 32 de la Constitución es una suerte de precompromiso para las generaciones futuras de excluir determinadas decisiones respecto de los derechos fundamentales. La idea del precompromiso implica dejar «fuera de la agenda política cotidiana y, por tanto, del debate público y del debate legislativo - de la regla de la mayoría, que solo vale para la agenda política del resto de cuestiones-189.

Como ya hemos mencionado líneas arriba, nuestra Constitución se inscribe en la tradición liberal democrática; esto significa que nuestro modelo de convivencia política se basa en la conjunción de los principios del liberalismo como de la democracia: libertad, derechos fundamentales de los individuos y los límites al poder del Estado e igualdad y sistema de representación democrática. Pues bien, el precompromiso establecido en 
el último párrafo del artículo 32 de la Constitución asegura una mayor probabilidad de alcanzar los ideales de libertad e igualdad.

Ahora bien, ¿por qué la jerarquía de la Iglesia católica hace esta propuesta? En primer lugar, nos parece que no se le escapa que la gran mayoría de peruanos son personas creyentes y que ante la eventualidad de un referéndum tendría altas posibilidades de éxito. Y, en segundo lugar, de este dato sociológico — de la mayoría creyente — cree la jerarquía de la Iglesia católica que es posible otorgar mayores derechos fundamentales a las mayorías - en este caso, a los creyentes - y restringir o suprimir derechos fundamentales a las minorías. Esta forma de proceder es ciertamente errónea, ya que los derechos fundamentales son regulados y gozamos de estos en virtud de la igual dignidad de todos los varones y mujeres, independientemente de su preferencia sexual o su creencia religiosa.

También, desde este dato sociológico, la jerarquía de la Iglesia católica cree que es posible interpretar la Constitución a partir de la Biblia y de los escritos teológicos ${ }^{90}$. Así, por ejemplo, la Conferencia Episcopal entiende la convivencia social como creación divina, al afirmar que «Dios los creó varón y mujer» (Gn 1, 27). Esta diversidad y complementariedad sexual tampoco es un mandato de la persona humana, ni del Estado, ni de la ley, sino que es creación de Dios para el bien del género humano, o como enseñan las Sagradas Escrituras: «Por esta razón deja el hombre a su padre y a su madre y se une a su mujer, y los dos se hacen uno solo» (Gn 2, 24). Dios dijo al hombre y a la mujer: «Crezcan y multiplíquense» $(G n 1,28)$. «Lo que Dios unió que no lo separe el hombre» (Mt 19, 6). «El matrimonio es la unión natural y perpetua del hombre y la mujer que, en una comunidad de vida, de manera digna, procura el propio bien de los cónyuges, la generación responsable de los hijos y la mejor educación de estos ${ }^{{ }^{91}}$. Una vez más, las reglas de la convivencia social están recogidas en la Constitución y al señalar el carácter laico del Estado proscribe el uso de criterios trascendentales o metafísicos o revelaciones o teológicos en su interpretación.

La jerarquía de la Iglesia católica afirma igualmente que la unión civil no matrimonial «no respeta el camino natural» o que «va en contra de la ley natural $\gg^{22}$. Estas son afirmaciones de gran impacto emocional; lo que buscan es apelar a lo irracional y a los temores que portamos a fin de

90 Fernández Valle 2008: 612.

91 Consultado el 5 de marzo de 2014 de http://www.rpp.com.pe/2014-04-03-conferenciaepiscopal-peruana-se-pronuncia-sobre-proyecto-de-union-civil-noticia_681736.html 92 Consultado el 5 de marzo de 2014 de http://www.rpp.com.pe/2014-03-29-cipriani-plantea-referendum-sobre-aborto-y-union-civil-noticia_680551.html 
inclinar la discusión a su favor; curiosamente, las personas que utilizan estos argumentos nunca los desarrollan, porque saben que carecen de contenido concreto.

Por otra parte, la mención de la palabra naturaleza es para decirnos que el matrimonio es una institución natural dada por Dios, para que una mujer y un varón hagan vida en común; es decir, se naturaliza la convivencia social y sus problemas para decirnos que no hay otras soluciones posibles, porque así viene dada por la naturaleza y por Dios. Para decirlo de otra manera, se nos dice que las instituciones sociales vienen dadas por la naturaleza y lo natural es expresión de lo divino; con esto se intenta cambiar el desarrollo de las sociedades: primero fueron las simples uniones entre personas, digamos que esto es lo natural (el hecho social ${ }^{93}$ ); luego, al hacerse más compleja la convivencia humana, surgen las instituciones, entre ellas el matrimonio y su regulación.

Del mismo modo, estos argumentos se utilizan como argumentos de autoridad, que encierran una verdad incuestionable y que es revelada a un pequeño grupo, que a su vez siente la obligación de imponerla a todos. Pero en democracia y en la nuestra, la verdad se construye escuchando las razones del otro e incorporando sus valores coincidentes; entre todos construimos lo razonable, que, además, está «sometido a verificación intersubjetiva ${ }^{94}$. Al ser portadores de la verdad, se hace imposible iniciar procesos de argumentación, aptitud que no se condice con los principios del liberalismo democrático.

Luego, la jerarquía de la Iglesia católica afirma que «se requiere de una modificación constitucional ${ }^{95}$. Este sintagma solo puede entenderse, según la verdad revelada a la Iglesia, como la posibilidad de elevar a rango constitucional el enunciado normativo del artículo 234 del Código Civil; para la Iglesia, «el matrimonio es la unión natural y perpetua del hombre y la mujer.... ${ }^{96}$. Pues bien, esta propuesta contraviene lo dispuesto en el último párrafo de la disposición normativa contenida en el artículo 32 de la Constitución y los instrumentos internacionales de derechos humanos ratificados por el Estado peruano, ya que significaría una disminución del derecho fundamental al matrimonio.

93 El Ministerio de Justicia señala que «la asignación del atributo "natural" a la institución matrimonial solo puede interpretarse en el sentido de que el hecho social que permite establecer jurídicamente su institucionalización precede a la formación del Estado y a su reconocimiento constitucional» (p. 19).

94 Savater 2007: 209.

95 Consultado el 5 de marzo de 2014 de http://www.rpp.com.pe/2014-03-29-cipriani-plantea-referendum-sobre-aborto-y-union-civil-noticia_680551.html

96 Consultado el 5 de marzo de 2014 de http://www.rpp.com.pe/2014-04-03-conferenciaepiscopal-peruana-se-pronuncia-sobre-proyecto-de-union-civil-noticia_681736.html 


\section{Conclusiones}

1. La segunda disposición normativa constitucional (DNC2) sobre el matrimonio expresa un contenido normativo (CN) conjuntivo conformado por las siguientes normas constitucionales, las cuales garantizan la titularidad y el ejercicio del derecho al matrimonio a todos los ciudadanos y ciudadanas:

DNC2CN1: «El matrimonio es la unión estable y voluntaria entre dos personas de sexo diferente».

DNC2CN2: «El matrimonio es la unión estable y voluntaria entre dos personas del mismo sexo».

DNC2CN3: «El matrimonio es la unión estable y voluntaria entre dos personas intersexuales, travestis, transgénero, transexuales».

2. De DNC2 podemos delimitar el derecho al matrimonio. Los titulares de este derecho son todos los varones y mujeres de acuerdo con el contenido normativo conjuntivo de DNC2 y las que eventualmente sean exigidas por la ley. Asimismo, su objeto es un agere licere; es decir, una libertad. El único que decide (autonomía) darse la norma de casarse es su titular y nadie "puede disponer jurídicamente de su conducta en ese espacio vital o jurídico objeto del derecho fundamental $»^{97}$ al matrimonio. La faceta negativa de esta libertad reside en no contraer matrimonio si uno no anhela hacerlo ${ }^{98}$.

El contenido de este derecho es la unión estable de dos personas - varón y mujer, varón y varón, mujer y mujer, e intersexuales, travestis, transgénero, transexuales entre sí-, con la finalidad de fundar una familia, que no incluye la exigencia de la procreación. Los límites generalmente aceptados son: no pueden contraer matrimonio los infantes, la prohibición de la poligamia y del incesto.

3. Los anteproyectos, aparte de presentar una inconsistencia lógica, están insuficientemente argumentados y no hacen un uso adecuado del principio de igualdad como exigencia de generalidad o igualdad de trato jurídico, en virtud del cual todas las personas nos encontramos vinculadas a las mismas normas y tribunales. La vulneración de la igualdad de trato se manifiesta en la imposibilidad de ejercer el derecho al matrimonio, vulneración que ninguno de los anteproyectos remedia.

Lejos de salvaguardar esta manifestación del principio de igualdad y no discriminación, compromete aún más su plena vigencia. En un entorno 
social tan adverso como el nuestro para las parejas con identidad sexual, identidad de género y orientación sexual distinta de las heterosexuales, significaría empeorar, aún más, la situación social y jurídica de estas personas. Al diferenciarlas se reforzaría en el imaginario social su condición de ciudadanos y ciudadanas de categoría inferior a los matrimonios heterosexuales ${ }^{99}$.

4. A fin de promover la plena vigencia de la Constitución y que la convivencia política gire en torno a sus principios rectores, habrá que entender -ya sea por vía de la interpretación constitucional o mediante la reforma de la Constitución y la modificación del Código Civil- que el artículo 4 de la Constitución, concordado con el artículo 234 del Código Civil, permite el ejercicio del derecho al matrimonio a las personas del mismo sexo, intersexuales, travestis, transgénero, transexuales. $Y$ en cuanto al artículo 5 de la Constitución, concordado con el artículo 326 del Código Civil, sí tendría que reformarse en el sentido de eliminar el sintagma «un varón y una mujer», con la finalidad de establecer un régimen único para las uniones de hecho, que incluya a las personas del mismo sexo, intersexuales, travestis, transgénero, transexuales.

5. El Estado deja pasar, inexplicablemente, una oportunidad para «armar» adecuadamente el ordenamiento jurídico del matrimonio y la unión de hecho para todos los ciudadanos y ciudadanas, y de este modo cumplir con sus obligaciones constitucionales y las del derecho internacional de los derechos humanos respecto de este tema.

6. Este debate pone en evidencia la fragilidad del Estado laico, que exige que las ideologías religiosas, sus creencias y prácticas deban armonizar con el pleno respeto de la Constitución y el resto del ordenamiento jurídico. En este sentido nos parece que la intervención de la jerarquía de la Iglesia católica ha sido poco afortunada; da la impresión, a veces, que actúa más como un poder fáctico que busca imponer su ideario político autoritario. Debe tenerse siempre presente que este tipo de acción política de los poderes fácticos está prohibida por nuestra Constitución y el Estado constitucional de derecho. 


\section{REFERENCIAS BIBLIOGRÁFÍCAS}

ABRAMOVIC, Víctor y COURTIS, Christian (2004). Los derechos sociales como derechos exigibles. Madrid: Editorial Trotta.

ALARCÓN CABRERA, Carlos (2004). «lgualdad y derechos». En Jerónimo Betegón, Francisco Laporta, Juan Ramón de Páramo y Luis Prieto Sanchís (coordinadores). Constitución y derechos fundamentales. Madrid: Ministerio de la Presidencia, Secretaría General Técnica y Centro de Estudios Políticos y Constitucionales.

AÑÓN, María José (2001). Igualdad, diferencias y desigualdades. México D. F.: Editorial Fontamara.

ÁLVAREZ, Silvina (2002). «La autonomía personal». En Elías Díaz y José Luis Colomer (editores). Estado, justicia, derechos. Madrid: Alianza Editorial.

BARBERA, Augusto (2000). Le basi filosofiche del costituzionalismo. Roma: Editori Laterza.

BASTIDA FREIJEDO, Francisco J.; VILLAVERDE MENÉNDEZ, Ignacio; REQUEJO RODRÍGUEZ, Paloma; PRESNO LINERA, Miguel Ángel; ALÁEZ CORRAL, Benito, y FERNÁNDEZ SARASOLA, Ignacio (2004). Teoría general de los derechos fundamentales en la Constitución española de 1979. Madrid: Editorial Tecnos.

BOVERO, Michelangelo (2002). Una gramática de la democracia. Contra el gobierno de los peores. Madrid: Editorial Trotta.

COLOMER, José Luis (2002). «Libertad individual y límites del derecho. El liberalismo y sus críticos». En Elías Díaz y José Luis Colomer (editores). Estado, justicia, derechos. Madrid: Alianza Editorial.

\section{CONSTITUCIÓN POLÍTICA DEL PERÚ (1993).}

CORTE INTERAMERICANA DE DERECHOS HUMANOS (2003). Opinión Consultiva OC-18/03 de 17 de setiembre de 2003, solicitada por los Estados Unidos Mexicanos, Condición jurídica y derechos de los migrantes indocumentados. Consultado el 5 de marzo de 2014 de http://www.corteidh. or.cr/docs/opiniones/seriea_18_esp.pdf

(2012). Caso Atala Riffo y niñas vs. Chile, Sentencia del 24 de febrero de 2012. Consultado el 5 de marzo de 2014 de http://corteidh.or.cr/docs/casos/articulos/seriec_239_esp.pdf

CÓDIGO CIVIL DEL PERÚ. Decreto Legislativo 295.

CÓDIGO PROCESAL CONSTITUCIONAL. Ley 28237.

DEFENSORÍA DEL PUEBLO (2014). Opinión respecto del Proyecto de Ley 2647/2013-CR, que establece la unión civil no matrimonial para las personas del mismo sexo. Situación de los derechos fundamentales de la población LGBTI en el país. Consultado el 5 de marzo de 2014 de http://www. 
defensoria.gob.pe/modules/Downloads/informes/varios/2014/Informede-Adjuntia-003-2014-DP-ADHPD-2.pdf

DIEZ PICAZO, Luis María (2003). Sistema de derechos fundamentales. Madrid:Thomson-Civitas.

TRIBUNAL CONSTITUCIONAL DEL PERÚ (2004). Exp. 0045-2004-PI/TC, Demanda de inconstitucionalidad interpuesta por el Colegio de Abogados del Cono Norte de Lima, contra el artículo 3 de la Ley 27466, modificatoria de la Ley Orgánica del Consejo Nacional de la Magistratura. Consultado el 5 de marzo de 2014 de http://www.tc.gob.pe/jurisprudencia/2006/000452004-Al.html

(2005). Exp. 0025-2005-PI/TC y 0026-2005-PI/TC, Colegio de Abogados de Arequipa y otros, demanda de inconstitucionalidad contra parte de la Ley 26397. Consultado el 5 de marzo de 2014 de http:// www.tc.gob.pe/jurisprudencia/2006/00025-2005-Al\%2000026-2005Al\%20Admisibilidad.html

(2005). Exp. 5854-2005-PA/TC, Pedro Andrés Lizana Puelles contra la sentencia de la Segunda Sala Especializada en lo Civil de la Corte Superior de Justicia de Piura. Consultado el 5 de marzo de 2014 de http://www.tc.gob.pe/jurisprudencia/2005/05854-2005-AA.html

(2006). Exp. 2273-2005-PHC/TC, Karen Mañuca Quiroz Cabañillas vs. Sala Penal Superior de Emergencia para procesos con reos libres de la Corte Superior de Justicia de Lima. Consultado el 5 de marzo de 2014 de http://www.tc.gob.pe/jurisprudencia/2006/02273-2005-HC. html

FERNÁNDEZ VALLE, Mariano (2008). «Matrimonio y diversidad sexual: la lección sudafricana». En Roberto Gargarella (coordinador). Teoría y crítica del derecho constitucional. Buenos Aires: Editorial Abeledo Perrot.

FERRAJOLI, Luigi (2011). Principia iuris. Teoría del derecho y democracia. 1. Teoría del derecho. Madrid: Editorial Trotta.

GONZÁLEZ AMUCHASTEGUI, Jesús (2004). Autonomía, dignidad y ciudadanía. Una teoría de los derechos humanos. Valencia: Editorial Tirant lo Blanch.

LAPORTA, Francisco J. (2007). El imperio de la ley. Una visión actual. Madrid: Editorial Trotta.

MALEM, Jorge (2003). «La imposición de la moral por el derecho. La disputa Devlin-Hart». En Rodolfo Vázquez (compilador). Derecho y moral. Ensayos de un debate contemporáneo. Barcelona: Gedisa Editorial.

MINISTERIO DE JUSTICIA (2014). «Informe 2014-JUS/DGDH». Consultado el 5 de marzo de 2014 de http://3.elcomercio.e3.pe/doc/0/0/8/5/1/851029. pdf 
MORESO, Juan José (2009). La Constitución: modelo para armar. Barcelona: Editorial Marcial Pons.

NINO, Carlos Santiago (2013). Fundamentos de derecho constitucional. Análisis filosófico, jurídico y politológico de la práctica constitucional. Buenos Aires: Editorial Astrea.

ORGANIZACIÓN DE ESTADOS AMERICANOS (1969). Convención Americana sobre Derechos Humanos. Consultado el 5 de marzo de 2014 de http:// www.cidh.oas.org/basicos/basicos2.htm

ORGANIZACIÓN DE LAS NACIONES UNIDAS (1966). Pacto Internacional de Derechos Civiles y Políticos. Consultado el 5 de marzo de 2014 de http:// www.ohchr.org/EN/Professionallnterest/Pages/CCPR.aspx

. Observación General 20. La no discriminación y los derechos económicos, sociales y culturales (artículo 2, párrafo 2, Pacto Internacional de Derechos Económicos, Sociales y Culturales). Consultado el 5 de marzo de 2014 de http://tbinternet.ohchr.org/_layouts/treatybodyexternal/Download.aspx?symbolno=E\%2fC.12\%2fGC\%2f20\&Lang=en

PÉREZ LUÑO, Antonio Enrique (2007). Dimensiones de la igualdad. Madrid: Editorial Dykinson.

PÉREZ ROYO, Javier (2007). Curso de derecho constitucional. Madrid: Editorial Marcial Pons.

RED PERUANA TLGB y PROMSEX (2013). Informe anual sobre derechos humanos de personas trans, lesbianas, gays, bisexuales en el Perú 2012. Sin igualdad no hay justicia. Lima: Promsex.

SAVATER, Fernando (2007). La vida eterna. Madrid: Editorial Ariel.

TRIBUNAL CONSTITUCIONAL ESPAÑOL (2012). Sentencia 198/2012, del 6 de noviembre de 2012. Cámara de Diputados vs. Estado Español. Consultado el 5 de marzo de 2014 de http://www.tribunalconstitucional.es/ES/ JURISPRUDENCIA/Paginas/Sentencia.aspx?cod=20674 